has been systematically adopted, not a singlecase has occurred. Directions were also given to the nurses that if a child's eyes looked in any way red, it was to be taken at once to the hospital for a lrop of nitrate of silver solution (five grains to the ounce), to be dropped into the eye. This has very seldom been required, and, as stated, in no instance in the last 2000 labours has a case of ophthalmia occurred. This plan is remarkably simple, and the absence of any application, such as nitrate of silver, to the eyes renders it very easy of adoption by nurses and midwives. The success which has attended its use at the Jessop Hospital renders it worthy of more extended employment. Its success clearly depends on washing away secretions from and near the eyes before the child has opened them, and before infection has taken place. Strong evidence is thus afforded against the opinion often held, that it is whilst in the maternal passages that infection occurs. This is a point of much moment in the adoption of preventive means against the disease. A recent article by Dr. Iudwig Korn, "On the Prevention of the Blennorrhoea of the Newly Born," is very interesting, because he discusses this question, but especially as he was led to adopt very similar preventive measures to those I have described as being in use at the Jessop Hospital. His experience was gained at the Dresden Clinic for Women. "The method employed was the following. Every woman in labour was carefully cleansed. When possible they were put into a warm bath. After the hair on the genital organs had been clipped, the external parts were washed witli soap and irrigated with a solution of bichloride of mercury, 1 in 1000 . The ragina was washed out according to $K$ altenbach's method with a solution of bichloride, 1 in 3000 . In every case which appeared to be suspicious of blennorrhœa I rubbed the mucous membrane of the vagina and cervix with my finger, while the irrigation was made as Cohn recommended. During parturition these irrigations were repeated several times, before and after every digital examination. As soon as the head was born, the eyelids and the portions surrounding the teyes were scrupulously cleansed by means of cotton soaked in hydrant water. And especially all the srnegma was removed. We rubbed the cotton from the outer to the inner canthus, continually using fresh pledgets of cotton until the lids were perfectly clean. We particularly tried to prevent any opening of the eres before this cleansing process was finished." The results were very good. He thought it seemed evident that thus the eyes could not be infected while the child passed through the vagina. The sublimate solution for cleansing the ragina was reduced in strength, and it was only used before and after digital examination. When no examination was made, no sublimate solution was used. In such cases as this, nitrate of silver was formerly dropped into the eye. But, since it was supposed that infection did not take place during the passage of the child, it was no longer used. In all cases, however, every baby born in the institution was washed with simple water as described, without paying any regard to the previous cleansing of the parturient mother. The results were excellent. Three cases of ophthalmia only occurred in 1000 cases; one in the last 700, and not one in the last 420 .

2. Cannot something be done to diffuse information as to the curability of the lisease, and to enforce the necessity for immediate treatment in those cases in which it has occurred? Dr. David Mckeown brought before the Ophthalmological Society, in 1884, a very well elaborated scheme with such an object. He proposed to ntilise the Poor-law and birth-registration organisations. The Society adopted with slight modifications these suggestions, and communications were opened with the anthorities, and leading to no result, a deputation waited on the Local Government Board. I am not aware that in England any steps have been taken by the authorities. In Ireland, how ever, the importance of the matter was brought before the Poor-law medical officers, and also the midrvives. But in the absence of such an elaborate scheme much can be done in simpler ways. 'T he Society for the Prevention of Blind ness has issued a leaflet entitled "Adrice to Mothers who do not wish their Children to be Blind." Other societies have done something as well. To the parents or friends of babies brousht to the Sheffield General Infirmary we are not only now giving directions as to the serious nature of the disease, the need for the early treatment which

3 Archiv f Gynæcologie Translation in American Journal of Ophthalmology for November, 1887 . has been too often neglected, and the safety of eves imperilled or sight lost; but we give then a card which enforces these points, and which they are desired to preserve. The card has very similar but somewhat more brief directions to those suggested by the committee of the Opthalmological Society (Dr. McKeown's), and it reads as follows: "If a baby's eyes run with matter and look red a few days after birth, take it at once to a doctor. Delay is dangerous, and one or both eyes may be destroyed if not trected inmediately." Dr. Bell has succeeded in securing the voluntary assistance of the registration officers in Bradford, and in this way a slip with somewhat similar instructions to those just mentioned is given attached to the certificate when a birth is registered. This excellent plan may well be initated. I tried, moreover, some little time since, to obtain the assistance of the St. John Ambulance Association, with its extensive organisation, for the diffusion of knowledge respecting the gravity of this affection. I am sorry I did not succeed; perhaps someone else may do so. There are other ways in which by degrees information may be scattered, and in the end bear fruit; but, in conclusion, I would point out the great help which teachers of obstetrics can render by enforcing on their classes the two lessons this paper has attempted to set forth-viz., (1) That the disease is preventable by the adoption of simple measures; and (2) when it does occur, it yields to treatment if not delayed. To writers of text-books the opportunity and duty are equally great, if not greater, as are also those pertaining to the teaching of midwives.

Sheffield.

\section{THE COLOSTRUM CORPUSCLE OF HUMAN MILK.}

BY EDGAR BECKIT TRUMAN, M.D., F.C.S.,

SURGEON TO THE SAMARITAN HOSPITAL FOR WOMEN, TO THE NOTTINGHAM AND MIDLAND EYE INFIRMARY, AND BOROUGH ANALYST.

In November, 1886, I was consulted with respect to the following case.

F. F_- a single woman of twenty-three, had admittedly been confined at full term eighteen months previously. On a day of August, 1886, after a time during which she asserted herself to be pregnant, she showed to those about her a child of whom she declared herself to have been confined in the night. In November she attempted to affiliate this (or another) baby on a gentleman of good social position. She had milk in both breasts, and said that she was suckling the child. The gentleman prosecuted the girl for an attempt to extort money; and I was asked to examine the breast milk microscopically, one of the medical men in the case believing that the presence of colostrum corpuscles in the milk would prove "recent" delivery. The word "recent" being so exceedingly vague, I was asked whether I could furmish any proof that there had been a full-time or nearly full-time labour in the previous three months, this period only bearing on the case. The breasts were somewhat full, the nipples pointing downwards and outwards. By very gentle pressure, milk exuded on either side. This was not like the thin, opaque white milk of a suckling woman, but consisted of two portions : a thick, opaque white curd or cream, and a nearly transparent colourless serum. On microscopical examination there were to be seen numerous colostrum corpuscles, measuring 0014 of an inch in diameter, surrounded by close-lying multitudes of fat globules measuring $\cdot 001$ of an inch in diameter, as a maximum. On examining this same slide a few days afterwards, the colostrum corpuscles had disappeared, having fulfilled their life history by their normal termination-viz., bursting, - the burst envelopes being visible.

The inquiry resolved itself into two parts: firstly, to ascertain the significance of the colostrum corpuscle; secondly, to ascertain the usual condition of the breast milk three months after confinement. The literature of the subject is exceedingly scanty. MTost medico-legists mention the presence of colostrum in milk as characteristic of "recent" delivery, but dismiss the subject in a few words. Taylor refers to Donné's observations on this point. I have been unable to obtain the original memoir, but have found 
a large critique ${ }^{1}$ in English, from which I shall proceed to quote. In the course of his article, ${ }^{2}$ Donne says that normal milk is a fluid in which spherical globules of fat, and no other particles, are suspended. In colostrum there are some milk globules, but thex are irregular and disproportioned; some are large oil drops, and cannot be termed globules; this is imperfectly elaborated butter. The majority of other globules in colostrum are very small, look like dust in the midst of the fluid, and are mostly connected together by viscid matter. In addition to these, colostrum contains particles, some being very small, about one-hundred th of a millimetre ( .0004 of an inch) and others many times larger. These are slightly transparent, of a yellowish colour and granular appearance, and are made up of a multitude of small grains enclosed in a transparent envelope. They are not soluble in alkalies, but disappear in ether. This condition of milk is almost unchanged till the termination of the milk febricula; then occurs a gradual change. The number of granular bodies diminishes day by day ; the lactic globules acquire a more regular and definite form, and, without all being of the same size, differ less in this respect than was the case previously. These globules also, having previously been united, separate and move independently of each other. This change does not always occur at the same period. There are some traces of the primitive condition of milk twenty-four days after delivery, as a rule, to which there are exceptions. Sometimes the milk retains the character of colostrum far beyond the ordinary period, occasionally for months, or during the whole of lactation. Agglomeration of milk globules (fat) and presence of granular bodies are signs of milk either imperfectly formed or not of good quality. This modification takes place either in consequence of a lesion of the gland or of a change in the milk due to general disturbance of the health. A young mother eight days after labour had metro-peritonitis. As long as this continued the milk was full of granular bodies. The application of leeches relieved her, and from that moment the granular bodies ceased to appear. Pus may be found in milk ; this is not dissolved by ether, as the colostrum corpuscle is. The diameter of the milk globule (fat) increases the longer the time after delivery, but this sign is of no use to ascertain the age of the milk.

Taking them in the chronological order of their works, other authors write as follows. Beck ${ }^{3}$ says nothing on the subject. Guy ${ }^{4}$ makes no mention of it. Funke ${ }^{5}$ gives an exceedingly good plate, figuring the colostrum corpusele. Montgomery ${ }^{6}$ says: Donné states that the colostrum corpuseles occur in woman until the twentieth day, but that Simon never detected them after the eimhth or tenth; and, according to D'Outrepont, they usually disappear on the third day. Peddie says that changes in respect of the colostrum bodies go on in general until the tenth day, but sometimes it is three weeks before they cease. The conclusion is that we cannot lay much stress upon them in a judicial examination. Taylor ${ }^{7}$ does not mention this subject. Casper ${ }^{8}$ says that from six to eight days subsequently to labour the milk exhibits the colostrum corpuscle (a conglomerate of small fat particles held together by an albuminoid substance). Taylor ${ }^{9}$ gives a figure of the colostrum corpuscle, mentioning the fact that it is found in the first milk secreted after delivery, but says nothing as to its being any proof of recent delivery. Guy and Ferrier ${ }^{10}$ also give a figure, and say that the corpuscles are found in nill for the first five or six days, being of practical value only then. Ogston ${ }^{11}$ says that a microscopic examination of the milk, when they are present, may sometimes contribute to prove the recent occurrence of parturition. This solved all doubt in a case reported by Mr. Mercer Adam. The body of a new-born child, much decomposed, was found in a moor in the south of Scotland; it appeared to have been dead four or five weeks. Suspicion having fallen on a young woman who was supposed to have been delivered secretly about that time, she was arrested, and acknowledged that she had borne a child about a year and a half before, which she had nursed until within three months of her apprehension, but she firmly

1 British and Foreign Medical Review, 1838, vol. vi., p. 181. 2 Considerations on Milk, especially that of Nurses. By W. Al. Donne. 3 Elements of Jurisprudence, 1838. 4 Forensic Medicine, 1814. 5 Atlas of Physiological Chemistry, Cavendish Society, 1853 , 7 Principles and Practice of Medical Jurisprudence, 1863.

8 Medical Jurisprudence, New Srdenham Society, 1564.

9 Principles and Practice of Medical Jurisprudence, 1873, vol. ii., p. 375. 10 Forensic Medicine, $187 \overline{0}$

11 Lectures on Medical Jurisprudence, 1878, p. 159. denied having been recently delivered. No feasible plan of deciding the question appearing, someone suggested that her milk should be examined by the microscope. This was accordingly done, and it was found to abound in colostrum globules, showing that parturition had lately occurred. (As we shall see, this was an unwarrantable deduction, even although, as happened, the girl then confessed that she had recently given birth to a still-born child. It should be remembered, however, that colostrum has been met with in the milk of the human female so late as the seventh month after delivery. Barnes ${ }^{12}$ says that the "colostrum corpuscles are the still coherent clobules which result from the fatty metamorphosis of epithelial cells." They are characteristic of the tirst milk, and after a few days generally disappear. Donné states that they are present in manmitis during lactation, also when menstruation occurs during lactation. This latter fact has been verified by Barnes, who found that they were reproduced at every period, lasted for seven days or more, and then dis. appeared during the interval. Lehmann states that they are found in the course of any acute affection occurring during lactation. When these fat-containing globules follow their normal course and rupture, setting free their contents, the cell wall disappears in the galactophorous ducts, since they are not seen in the milk. A figure is given.

The value of this sign being so uncertain, I made a number of microscopical examinations of human milk myself. These were twenty-three in number; four of them were re-examinations at different periods of two cases, and in another case the milk differed in the two breasts, each examination beino recorded; so that, in all, eighteen women were the subject of observation. The colostrum corpuscles vary in size, in my cases measuring from $\cdot 0032$ to $\cdot 0005$ of an inch in diameter. They are generally of circular outline, but are sometimes irregular in shape; the border is finely indented, the colour is a light yellowish red, and the contents are finely granular. The fat globules, on the contrary, vary in diameter from 0013 to 0001 of an inch as maxima, and are met with of all sizes below this until they become invisible to a low power ( $\frac{1}{5}$ objective and No. 1 eye-piece). They are always circular in shape when the milk is recent; the border is perfectly unbroken in outline, the colour is a dead white, and the contents are transparent and homogeneous.

I will now proceed to narrate briefly, firstly, the cases in which I found colostrum corpuscles, and, secondly, those in which they were absent.

1. Cases in which colostrum corpuscles were present.No. 1 : Primipara; premature labour; had scarcely been free from coloured discharge for a day during the six and a half months of her pregnancy; child died at birth. There were numerous colostrum corpuscles; fat globules very small and wide apart.-No. 8: Same case, two weeks after (when the cavity of the uterus was normal in size).-No. 12: Three weeks after. I measured a colostrum corpuscle and found it to be 0011 of an inch. - No. 14:--Same case, four weeks after the labour. The microscopic appearances were much the same in all the four examinations; at the last examination the milk absolntely swarmed with the corpuscles. No. 7: Patient pregnant five months of her first child; corpuscles small, being -0007 of an inch.-No. 11: A week later. The corpuscles were larger; the measurement of one was 0014 of an inch.-No. 13: Multipara; last baby born twenty-six months ago, and weaned ten montlis. Patient has retroflexed uterus, and is not pregnant. In the breast milk were numerous colostrum corpuscles, measuring from $\cdot 0015$ to $\cdot 0029$ of an inch; fat globules $\cdot 0007$ of an inch and under.-No. 15: Suckling her four months' baby: colostrum corpuscles were very few.-No. 17: Married three years and a half, and has never been pregnant. Ever since marriage, for a week before the period the breast fills with milk, which passes away on the first day of the period. In this fluid there were several colostrum corpuscles. This patient had orarian prolapse, dysmenorrhcea, and dyspareunia, for which I subsequently remored the appendages. - No. 18: The right breast of No. 19. Suckling her baby of twelve months old, but not with this breast, which she has never been able to use for any of her six children. Is now menstruating. Milk thick and opaque; fat globules very small; colostrum corpuscles numerous, one of them measuring 0014 of an incl.--No. 21: Case of chronic ovaritis. 'Twenty-three months since last labour, and eleven since weaning. Swarms of corpuscles, measuring 
about 001 of an inch; and fat globules of all sizes.No. 22: Aged fifty-seven. Five months since last period, but had a slight show two days ago, due to mental emotion on account of approaching operation. Pelvis not examined. Breast was removed for carcinoma; on incising it afterwards a teaspoonful of milk was found in the ducts about the nipple, which contained well-formed fat globules measuring -0005 of an inch, and numerous colostrum corpuscles measur ing from $\cdot 0009$ to $\cdot 0016$ of an inch. Last child eight years old.-No. 23: Labour four years ago; lactation for nine months; has never been pregnant since, but has alwars had milk in the breast. This was a case of lacerated cervix and perineum, with dyspareunia.

1. Cases in which colostrum corpuscles were absent. No. 2: Three weeks after miscarriage at four months. No. 3: Three and a half months after labour at full term suckling.-No. 4: Two months and a half after labour at full term; suckling.-No. 5: Ditto.-No. 6 : Ditto.-No. 9 "Two nonths after labour at full term; suckling.-No. 10 Is suckling her baby of ten montls. Caune into hospital for ruptured extra-uterine foctation, for which I operated. No. 16: Two months and a half after labour at full term suckling.-No. 19: The left breast of No. 18. The milk of this the only breast ever used was most carefully examined for colostrum corpuscles, with a negative result. Baby twelve months old.--No. 20: Baby twelve months old; weaned three weeks; mother suffering from acute nephritis and albuminuria.

Thus in six cases (Nos. 3,4,5,6,9, and 16), which were suckling at or about three months, no colostrum corpuscles were found. They were also absent in three cases (Nos. 10, 39 , and 20 ) suckling from ten to twelve months, and in one (No. 2) three weeks after premature confinement at four months. The colostrum corpuscles were present (excluding the case in question and not reckoning re-examinations) in one case (No. 7) five months advanced in her first pregnancy in one (No. 2) a week after premature labour at six months and a half ; in one (No. 15) four months after labour at term, suckling going on (corpuseles very few in number) in three (Nos. 13,21 , and 23 ) at twenty-six months, twentythree months, and four years after labour, and ten months, eleven months, and three years and a quarter after weaning in one (No. 18) twelve months after labour, in the breast that was never used; in one (No. 22) after the menopause and in one (No. 17) where there had never been a preanancy. Thus, excluding Nos. 1 and 15 , the confinement had taken place in all these cases some considerable period previously, in one being eight years; one patient had never been confined, and one had never been pregnant.

It is evident, therefore, that the colostrum corpuscle is no proof of recent delivery, or of delivery, say, within the previous three months. It is a sign of incomplete develop ment of the products of the mammary gland, and in this way we get it with retroflexion of the uterus (No. 13), prolapse of the ovary (No. 17), incomplete action of the gland (No. 18), chronic ovaritis (No. 21), cancer of the oreast (No. 22), and dyspareunia with laceration (No. 23), in all which cases we get the irritative action of disease, instead of the normal healthy activity of the reproductive organs. In fact, the presence of the corpusele would tend to negative the supposition of a delivery followed by three months' suckling, as was the contention of the defendant in the case in point. In this case, if there were no other explanation of the presence of milk of the quality described in her breast, such as ovarian disorder \&c., we see that no improbability is incurred in supposing her milk supply to be the result of the confinement eichteen months previously; or she may have been confined three months before, the baby dying and the breast not being used. As a matter of fact, the child she produced was afterwards claimed in court by the parents, who swore that E. F- had paid them a sum of money to hire it for a time; the ultimate result being that she was sentenced by Mr. Justice Field to several months' imprisonment.

Nottingham.

BradFord Horst Amburanck.-The presentation to the Corporation of the horse ambulance provided by the workpeople of that town took place on Saturday last. In the absence of the Mayor, Alderman W. W. Wood (chairman of the Watch Committee) officiated as president during the ceremony, and on behalf of the Watch Committee and Corporation received the ambulance. The subscriptions amounted $£ 1464 s$. $3 d$.

\section{CASE OF MEDIASTINAL CANCER.}

\section{BY R. WHITTINGTON-LOWE, M.D.}

ON Sept. 30th last I received a message requesting me to call and see a patient who had come to Brighton about an hour before I saw him. He was a big, wille-chested man, aged sixty, whom I had attended a year ago for a rather severe attack of lumbago. He told me that he had been ill for three weeks, during which time he had lost flesh and strength. He had been complaining of pain across the epigastrium. He had seen two physicians in London, who informed him that he was suffering from rheumatism of the diaphragm. His pulse at this time was about 140 ; tempera. ture (mid-day) normal. The patient went into Norfolk for change, and consulted a doctor there, who confessed that the case puzzled him. His pulse kept about 140; and his temperature, when taken at about 12 mid-day was normal. At this time there were severe pains about the epigastric region, and as he did not find himself improving he determined to come to Brighton. I found him con siderably thinner than when $\mathrm{l}$ attended him last year. Complexion sallow; tongue inclined to be dry, and considerable thirst; pulse 144. He informed me that there had been no rise of temperature. This, howerer, I found was incorrect, as at my visit on Sept. 30th, at 6 P.M. the thermometer registered $101^{\circ}$; respiration 30 . Complete examination was postponed till the forenoon of the following day. The subjoined notes are extracted from my case-book, having been written at the dates stated, thus giving an additional interest to the case, and presenting the salient points as they occurred.

Oct. 1st.-Made careful examination of chest and abdomen. Unable to detect any well-marked departure from health beyond the rapid heart action and increased rapidity of respiration. There is a difference of vocal resonance and thrill, both being greater on the right side. Pulse at 11 A.M. 134, temperature $99^{\circ}$, and respiration 26 . Ordered a mixture containing tincture of strophanthus to be taken every third hour. At evening visit, pulse 140, temperature $100 \cdot 3^{\circ}$, and respiration 28 . Patient looks very ill, with an expression of consciousness of impending danger.

2nd (Sunday). - Patient much the same. I think badly of him. Proposed to patient that I should ask a brother physician to see him with me, which was agreed to. My colleague's examination did not elicit anything further; he is inclined to attribute the vague symptoms to rheumatic origin. Strophanthus to be continued, and a mixture containing paraldeliyde given at night. Pulse, respiration, and temperature much as before, rising in the afternoon and falling in the morning.

5 th.-Patient does not improve. This morning I think I can detect just a suspicion of fine crepitation over middle of left lung. No catching of breath or pain on deep inspiration. No expectoration. Patient looks very ill. Great thirst. Liver, kidneys, \&c., all apparently healthy. Urine acid ; sp. gr. 1030 ; deposits urates, and erystals of uric acid are seen under the microscope. Telegraphed to one of our leading consultants in London, who came down by the afternoon train and made a searching examination of the patient. Arrived at the conclusion that there was "a low sneaking inflammation of the base of the left lung about to develop"; at the same time confesses the case to be a most peculiar and obscure one. Ordered strophanthus to be continued, and an effervescent mixture with citric acid to be given. Patient to stay in bed, with poultices on.

7th.-CThis morning slight crepitation over base and middle of left lung still heard. Slight irritative cough; no expectoration. Other symptoms as before. Pulse 140 temperature $100^{\circ}$; respiration 30 . Ordered two grains of quinine to be given three times a day. Patient disliked the paraldehyde so much that I have substituted bromide of ammonia and small doses of liq. mur. morph. at night, and it has a capital effect. We have now to do with some slight inflammation of the left lung, but is this the primary disease or a symptom of something not detected? I think so. Was it this inflammation only now developing that caused the pulse to be 140 nearly a month ago? I think not. There was a little pure blood conghed up yesterday (not pneumonic sputa). Is it cancer affecting the lung?

15th. - Patient has been going on with very little change 